\title{
Reflective journals as a developmental tool in PAL
}

\section{Carolyn Gentle}

Plymouth University, UK

\section{Rachel Shaw}

Plymouth University, UK

\section{Sophie Scott}

Plymouth University, UK

\section{Abstract}

Reflection is frequently used as a means towards evaluating and improving performance. In the context of peer learning, post-session debriefs are reflective conversations between Peer Assisted Learning (PAL) leaders and their Academic Co-ordinators. Reflection-foraction (Killion and Todnem, 1991) is a good fit with peer learning which is typically actionoriented.

This case study considers the extent to which a PAL leader's professional capability and personal development may be further boosted by keeping a reflective journal. It raises the question whether or not there are tangible benefits to the journal-keeper in terms of their perceptions of their own learning, soft skills and employability.

A PAL leader at a UK university who kept a reflective PAL journal found the process enriching and it led to some changes in thought in respect of assumptions about what PAL success could look like.

Keywords: reflection-for-action; confidence; writing cycle. 


\section{Background}

UK universities already make use of reflection for learning. We could be confident that a second year student at Plymouth University would be familiar with the concept of reflection, although this would not necessarily mean that they were inclined to adopt a reflective approach. Furthermore, we knew that the Peer Assisted Learning (PAL) debrief between leaders and programme academics offers regular opportunities for informal reflective peer discussion. We were, however, also aware that in practice, debriefs are frequently more focused on description and forward planning, than analysis and evaluation. We were therefore interested to know whether structured written reflection could generate more or richer reflexivity.

Moon (1999) identifies five stages in reflection: noticing - making sense - making meaning - working with meaning - transformative learning. Schön (1991) suggests that reflection can take two forms: reflection-in-action, which occurs during an event or process, and reflection-on-action, coming after the event. Killion and Todnem (1991) claim that reflective learning ought not to be concerned only with understanding but with its application to future decisions and actions: reflection-for-action.

\section{Case study}

According to Hagyard and Watling (2011, pp.178):

The most effective way to introduce students to researching and developing research-mindedness is to focus on real and topical examples of research which have an impact on everyday lives.

This project was an attempt to achieve this. Ethical approval was applied for and granted in advance of September training 2013. During training all 160 trainee PAL leaders from 19 subject areas were invited to participate. This case-study is based on the reflections of the sole PAL leader (S) who succeeded in maintaining a PAL journal for the whole academic year. S was a second year Physical Geography with Geology student. 2013 was the first year of PAL in Earth Sciences and therefore she had not experienced sessions as a first year. After training she was in a subject group of 14 leaders, had a leader partner, 
and a Peer Assisted Learning Scheme (PALS) group of 24 students. The programme had decided that sessions would be held every three weeks.

$S$ made seven journal entries based on seven PAL sessions, followed by a final entry evaluating the use of the reflective journal. She was provided with guidelines based on the stages identified by Moon (1999) and after Gibbs' Reflective Cycle (1988). Permission to use her data in this case study was not required since she is one of the authors of this article.

This is a skeleton outline of the structured writing instructions she was asked to follow:

- Description of the PAL session: What did I do, see, hear?

- Interpretation and rationale: What was the reason for this?

- Evaluation: How was this useful/relevant? What was its impact on leader(s) and students?

- Implications: What have I learnt and how can I apply this?

Thus S experienced the benefits of maintaining a writing cycle (Campbell-Evans and Maloney, 1998).

\section{Description}

S entered accounts of each PAL session:

We had planned on getting our students to talk to each other about how they think university has changed them as a person and what they think about differently now.

...proof-reading your essay, figure captions, and how to find journals...getting our students to look at a page of a journal with references in small groups to give them an idea of how they can put references within their own work. 


\section{Interpretation}

In each entry $S$ analysed how and why they selected specific activities:

The reason behind getting the students to talk about their experiences was to get them thinking about what they have achieved and being able to talk it over with others may get them to realise the extent...uni has changed them.

The activities were all to build up confidence for presenting... It also gets the students to talk to each other and feel more at ease with each other thus making it less nerve wracking when presenting.

S also reflects on her own experience, feelings and behaviour during sessions: it 'makes me realise how difficult it is not to give answers'; and on what they had learnt from having only one student, where 'there are no other students... [with whom] ideas and discussions can take place so you have to make sure you are careful about not teaching them'.

The entries evidence the consideration given to selecting relevant topics, activities and discussions.

\section{Evaluation}

Leaders sometimes consider low attendance a reflection on their performance. In debriefs it is often regarded as disappointing. $S$ was frank about low attendance but used the journal to articulate a nuanced perspective. Her interpretations go beyond the leader analysis typical during debrief conversations. She is also proactive and solutions-oriented:

Poor attendance has not been a bad thing - it has helped me change plans quickly and get to know people better. However, [it should be] addressed more at the start of the year (specific lecture.../PALS sessions on timetables/PALS session during fresher's week)...topics that are useful - like fieldtrips and revision.

S also discussed the challenge of coaching students towards an independent style of learning where they become used to sourcing information themselves: 
The group had lots of questions about minerology and did seem reluctant to look in the textbooks in front of them...Someone kept asking us the same questions and we are not allowed to give answers.

$S$ puts herself in the students' position to interpret their behaviour and concludes that, despite the challenges and student resistance, the activity is a useful one:

They are still getting used to university and how to work effectively through the need to refer to textbooks and to gain a better understanding of being more proactive in their learning.

As in the previous section, she also discussed how PAL supported her own development:

It was useful not only to the students but also to myself going over presentations and skills as I have my own presentation to do in a few weeks.

Even though no-one turned up, [preparation for] the session has helped me think about my own revision and how to revise best

PALS overall has helped me immensely with confidence issues, presenting to others, and going over previous work has helped me academically and will definitely help me with my future career.

These honest, perceptive and mature written reflections demonstrate that there may be much to say that does not typically emerge during a debrief discussion.

\section{Implications}

S expresses expert knowledge in her own context:

Working round the timetable for everyone is difficult, but feel it would be more effective to hold a session towards the middle of the day after a lecture, I think this may have been the reason for the lack of students as the session was held in the middle of a four hour break. 
If we have future PALS sessions with only one student, I know we can adapt what we had planned and still have a good session.

S ascribes an improvement in soft skills to PAL: 'better communication skills is something that will help me'; academic performance, confidence and employability:

This topic is very relevant to PALS, my course and my future life...it helps to give me self-confidence, and is a great skill for a job.

The subject was good to get me thinking about minerology again and to go over what I thought I knew about minerals. I realised how much I had forgot.

Donelan's (1999) view that leaders are major beneficiaries in peer learning contexts seems to be borne out by the experience of this leader in respect of her own subject learning as well as development of soft skills.

\section{Evaluative journal entry}

At the end of the journal-keeping period, $S$ completed a final entry evaluating whether she thought keeping a journal for PAL influenced how she and her partner planned and delivered sessions:

I think overall the PALS journal did influence my PALS process greatly and made me consider wider aspects, like my future skills and why students didn't turn up; ... It also helped in getting me to think more in depth, which helped improve my reflective skills.

She thought she detected a difference between her own approach and that of her partner and she suggests the journal-keeping played a part: 
I think for it [journal] to truly influence and effect the planning and running of sessions, my fellow PALS leader should have completed a reflective journal too...For instance sometimes when planning together they did not put much thought into a task...it was my decision to keep a reflective journal... as it does provide you with a greater insight.

She further observes - '[it] helped me focus on ideas in the debrief sessions'. This is an interesting outcome as it may indicate the potential for journal-keeping to have a qualitative impact on PAL debriefs.

\section{Commentary}

The consistent quality of the evaluative entries supports the use of journals for professional development and suggests they can exceed the reflexivity achieved in those debriefs which are insufficiently critical and where, for example, embarrassment might impede the analysis of reasons for low attendance.

The perceived personal and academic benefits of peer learning to leaders (Donelan, 1999; Hilsdon, 2014) are articulated by $S$ in all her entries:

There are significant advantages to be had if students are convinced of the benefits of learning to learn, self-awareness, and taking ownership and responsibility for personal development (Keenan, 2011, p. 69).

S contrasted her own with her partner's approach to planning sessions and claimed journal-keeping was a contributory factor in the difference. She describes how she sought to influence her partner, thereby demonstrating a nascent leadership skill.

S also comments that her contributions to debriefs were more thought-out as a result of journal-keeping. This is an interesting observation - Bulpitt and Martin (2005) suggest that reflection can be enhanced by in-class sharing, so $S$ may have had an enriched experience of debriefs. 


\section{Conclusion}

The aim of the project was to determine whether keeping a PAL journal enriches PAL sessions and supports leader personal development. S used the journal to reflect on what took place and how this could influence future sessions. Her entries suggest that she found the process helpful in interpreting events and informing future sessions. She also charted personal development milestones.

This outcome indicates that there is scope for wider piloting of journal-use in PAL. The journal design in this case study accorded with the aims of this small-scale project. Refining the leaders' writing instructions to probe reflection-for-action and its subsequent implementation may enable greater precision in the discussion of longitudinal and developmental outcomes.

From this case study it is difficult to generalise. Although the majority of leaders might not want to keep a journal, at Plymouth we are introducing written reflection at the beginning of debriefs so that all leaders will have an individual reflective moment followed by the usual group discussion. For $\mathrm{S}$, written reflection was a powerful tool for professional and personal development. In order to really benefit PAL through journal-keeping, it would need to be widely adopted. However, this case study indicates there can also be benefits from partial take-up and that these benefits are wide-ranging.

\section{References}

Bulpitt, H. and Martin, P.J. (2005) 'Learning about reflection from the student', Active Learning in Higher Education, 6(3), pp. 207-217.

Campbell-Evans, G. and Maloney, C. (1998) 'An analysis framework for reflective writing', Australian Journal of Teacher Education, 23(1), pp. 29-38.

Donelan, M. (1999) 'SI leaders: the real winners', National Conference on Supplemental Instruction. University of Missouri, Kansas City, USA 20-22 May. 
Gibbs, G. (1988) Learning by doing: a guide to teaching and learning methods. London: Further Development Unit.

Hagyard, A. and Watling, S. (2011) 'The student as producer: learning by doing research', in Hartley, P., Hilsdon, J., Keenan, C., Sinfield, S. and Verity, M. (eds.) Learning development in higher education. Basingstoke: Palgrave Macmillan, pp. 169-182.

Hilsdon, J. (2014) 'Peer learning for change in higher education', Innovations in Education and Teaching International, 51(3), pp. 244-254. Available at: http://www.tandfonline.com/doi/pdf/10.1080/14703297.2013.796709 (Accessed: 12 August 2015).

Keenan, C. (2011) 'A personal development planning perspective on supporting student transition in higher education', in Hartley, P., Hilsdon, J., Keenan, C., Sinfield, S. and Verity, M. (eds.) Learning development in higher education. Basingstoke: Palgrave Macmillan, pp. 67-78.

Killion, J.P. and Todnem, G.R. (1991) 'A process for personal theory building', Educational Leadership, 48(6), pp. 14-16.

Moon, J. (1999) Reflection in learning and professional development. London: Kogan Page.

Schön, D. (1991) The reflective practitioner: how professionals think in action. Aldershot: Ashgate Publishing Ltd.

\section{Author details}

Carolyn Gentle is PALS Co-ordinator at Plymouth University. As a Senior Lecturer in ELT and TESOL she published language learning materials for overseas students and edited a Research Informed Teaching publication in the UCLan RiT Impact Series. Her research has addressed the management of online 'classrooms', the use of technical tools for synchronous online interaction, and e-assessment. Currently she is mostly concerned with scaffolding PALS leaders as pedagogic researchers and following their lead. 
Rachel Shaw is a Research Assistant for the Peer Assisted Learning Scheme (PALS) and lead coordinator for the PALS in Partner Colleges project at Plymouth University. Having completed her doctorate in Psychology, her interests are now centred around the dynamics of peer learning and support within the PALS framework at university and colleges of further education.

Sophie Scott is an Earth Science graduate from Plymouth University who enjoyed working as a PALS leader for an academic year. She then took on the role of a senior PALS leader for a second year after witnessing the benefits and skills the role brought to first year students as well as leaders, particularly brought to light by completing a reflective journal. This encouraged her to volunteer as an ambassador in driving learning in Earth Science based on work in the field. 